\title{
Applying Participatory Design with Users with Intellectual Disabilities
}

\author{
Julio Abascal, Myriam Arrue and Juan Eduardo Pérez \\ University of the Basque Country/Euskal Herriko Unibertsitatea, \\ Egokituz Laboratry of HCI for Special Needs, \\ Manuel lardizabal 1, 20018 Donostia-san Sebastián, Spain \\ julio.abascal@ehu.eus, Myriam.Arrue@ehu.eus
}

\begin{abstract}
This paper presents an experience of participatory design with people with intellectual disabilities. The main goal was to create a Sheltered Social Network intended to train people with cognitive disabilities in the use of social networks and to allow the early detection of any type of danger they could face when they use a regular social network. In the first phase, we designed a strategy to allow the users to participate in the discussions without restrictions or barriers. In the second phase, we successfully applied this strategy in order to develop the Guremintza social network.
\end{abstract}

\section{Keywords}

Participatory Design · Intellectual Disabilities

How to cite this book chapter:

Abascal, J., Arrue, M. and Pérez, J.E. 2020. Applying Participatory Design with Users with Intellectual Disabilities. In: Loizides, F., Winckler, M., Chatterjee, U., Abdelnour-Nocera, J. and Parmaxi, A. (eds.) Human Computer Interaction and Emerging Technologies: Adjunct Proceedings from the INTERACT 2019 Workshops. Pp. 321-326. Cardiff: Cardiff University Press. DOI: https://doi.org/10.18573/ book3.ao. License: CC-BY 4.0. 


\section{Introduction}

The Egokituz $z^{1}$ Laboratory of Human-Computer Interaction for Special Needs was created in 1985. Through this time, Egokituz obtained experience in participatory design working with people with sensory and physical disabilities. These experiences were principally focused to the development of computer mediated communication and navigation systems. In these cases, the most difficult challenge was the communication with the users. Once overcome this barrier, the participatory design was developed following common procedures for this methodology.

When we were contacted to create a social network for people with intellectual disabilities we had no previous experience in these types of disabilities and we found scarce references to help us. Therefore, we adapted our procedures on the progress with the assistance of their educators and care staff.

As a result we designed the Guremintza $a^{2}$ sheltered social network following participatory design principles with the close participation of the users in order to collect their objectives, interest, likes, and restrictions. After a five months period of testing, the social network is currently fully operational and deployed in the industrial group Gureak ${ }^{3}$ created to assist the full social integration of people with intellectual disabilities through employment. In this paper, we describe the methods we adopted to make possible participatory design with people with intellectual disabilities.

\section{Development of Guremintza}

Gureak approached the Egokituz Laboratory of HCI for Special Needs to discuss the possibility of creating a social network intended to train people with cognitive disabilities in the use of social networks and to allow the early detection of any type of danger they could face when they use a regular social network. We agreed to create a work team composed of Gureak, Lotura (a small company specialized in accessible Web Design), and two laboratories of the University of the Basque Country: Egokituz (specialized in accessible HCI design) and

\footnotetext{
${ }^{1}$ Egokituz is the Basque word for "Adapting".

2 Guremintza means "Our Expression" in Basque Language.

${ }^{3}$ Gureak (meaning in Basque Language "Our People") is a Basque group of companies, which generate and manage steady work opportunities, suitably adapted, for persons with disabilities, with priority on people with intellectual disability. It provides jobs for more than 4000 people with diverse types of disabilities (39\% cognitive, $16 \%$ mental illness, $6 \%$ physical, $22 \%$ sensory, $17 \%$ no disabilities) [1].
} 
Aldapa (specialized in Data Mining and Machine Learning). We also agreed to apply a participative design methodology.

\subsection{Requirements for the design of the Guremintza social network}

In the firsts meetings, the following main requirements for the design of the Guremintza Social Network were stablished:

- Features: a) Accessible for people with cognitive, physical and sensory disabilities. b) Multilingual structure with access in Basque, Spanish and English languages. c) Personalized support to each user. d) Fully privacy protection (by means of codification techniques that made the users remain anonymous).

- Functionality: a) Periodical collection of activity data (only available to the supervisor) to follow the activity in the network. b) Early detection of possible misuses or dangers, triggered to a selected supervisor when unusual usage occurs. c) Testbed for research: data-mining techniques used to build dynamic user models in order to allow adaptive interaction.

- Design methodology: User centered design based on participatory design.

\section{Participatory design with users with intellectual disabilities}

We started having meetings with a group of seven selected users with diverse intellectual disabilities (four with Down syndrome and three with mental disabilities) who had previous experience in the use of computers. In these first meetings, we detected that the participant users tended to remain silent, deviate their interventions to other topics and provide positive answer to all the questions. Gureak care personnel, who had long experience in participatory decision taking meetings with people with disabilities, soon detected that the users were intimidated by the technicians and therefore they were not behaving as they did usually. Initially they supposed that after a number of meetings the users would become more familiar with the technicians and would freely participate, but it did not happen. Therefore, a new strategy was studied.

In addition, participatory Design [Schuler, 93] with users with cognitive disabilities requires special procedures that allow the eliciting of requirements while trying to avoid asking direct questions that could be impossible for some people with cognitive restrictions to answer [Dave, 2013]. Therefore, each consultation was reworded in such a way that was easy to answer for the users. In this way, we found an intelligible way for each question. For instance, initially we used paper mock-up versions to identify the requirements and difficulties that users had using them. 


\subsection{Design of an ad hoc participatory design methodology}

We conceived some special procedures for participatory design with people with cognitive disabilities:

Two boards were formed for the design process: the Users Board and the Designers Board.

The Users Board was composed of six workers of Gureak, four with Down syndrome and two with mental diseases. All of them had some basic experience in using computers. There were assisted by two educators of Gitek (the R\&D team of Gureak). This board participated in all the design and development phases (functionality, interface, look \& feel, etc.) and validated each prototype. They were regularly informed about the progress of the project.

The Designers Board was composed of four people from the University of the Basque Country (in charge of conception, accessibility, usability, usage data management, coordination, and dissemination); one person from Lotura (devoted to development, implementation, and maintenance); 2 people from Gitek (for the assessment on user needs and coordination with the Users Board). This board converted the design decisions made by the Users Board into design specifications, and developed them.

With respect to the procedure, the technical staff avoided any type of manipulation of the decisions made by the Users Board to be fair to them. Members of the Users Board were punctually informed about the results of the Design Board meetings. Only when proposals from the Users Board could not be implemented they were asked to select an alternative. This procedure very much enhanced the interest and participation of the users.

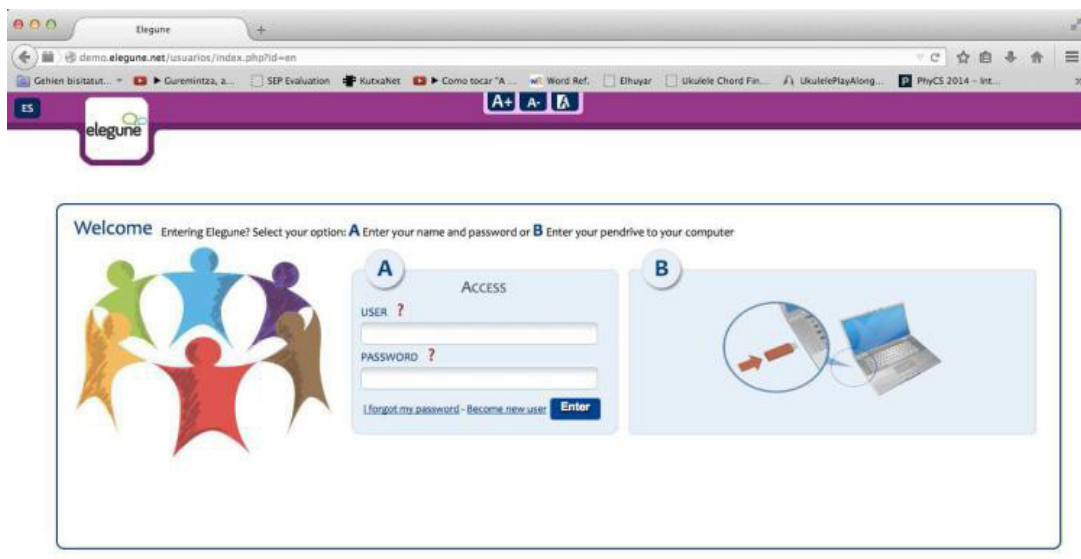

Fig. 1: Registering and entering: write name/password or Insert pen drive. 
Both boards meet separately, but coordinated by Gitek. They had fortnightly meetings for seven months. A paper mock-up version of the social network was initially used to identify the best procedures and the difficulties that users have in using them. After this period, a first fully functional prototype was tested by the users for five months. After fixing the problems detected by them, the final version of the social network was designed, tested and deployed. Currently, Guremintza is fully operational in the Gureak industrial group. In addition to training/ supervising people in the use of social networks, it is actually an effective way for internal communication to encourage personal relationships among the workers.

\section{Conclusions}

A number of conclusions can be drawn from this experience:

- Participatory design with people with cognitive disabilities is possible, provided that adequate procedures are designed to collect their opinions.

- Participation of the users in the design allows a progressive development based on users' needs and capabilities, always ensuring their understanding of the application.

- This method minimizes the possibility of including barriers that are rooted in the basic design and, therefore, cannot be removed.

- Participatory design increases the users' affinity to the resulting application and increases its usage.

\section{References}

1. Gureak. https://www.gureak.com/en/ (last accessed May 2, 2019)

2. Schuler D., Namioka A. (eds) (1993) Participatory Design: Principles and Practices. Lawrence Erlbaum Associates, Hillsdale, NJ.

3. Dawe M. Design Methods to Engage Individuals with Cognitive Disabilities and their Families. https://pdfs.semanticscholar.org/e391 /b31f8e3c7fd0fac7f594fdc08fed6f4c5d2f.pdf (Last accessed: May 7, 2019)

4. Sahib N.G., Stockman T., Tombros A., Metatla O. (2013) Participatory Design with Blind Users: A Scenario-Based Approach. In: Kotzé P. et al. (eds) INTERACT 2013. LNCS 8117. Springer, Berlin, Heidelberg

5. Satterfield D., Marc F. (2017) User Participatory Methods for Inclusive Design and Research in Autism: A Case Study in Teaching UX Design. In: Design, User Experience, and Usability: Theory, Methodology, and Management, 186-197.

6. Sitbon L., Farhin S. (2017) Co-Designing interactive applications with adults with intellectual disability: a case study. OzCHI '17, Brisbane

7. Guremintza in YouTube: https://www.youtube.com/watch?v=aZjIbrPj7OE 